\title{
Content Matters: Neuroimaging Investigation of Brain and Behavioral Impact of Televised Anti-Tobacco Public Service Announcements
}

\author{
An-Li Wang, ${ }_{1}^{1}$ Kosha Ruparel, ${ }^{2}$ James W. Loughead, ${ }^{2}$ Andrew A. Strasser, ${ }^{1,2}$ Shira J. Blady, ${ }^{2}$ Kevin G. Lynch, ${ }^{2}$ \\ Dan Romer, ${ }^{1,2}$ Joseph N. Cappella, ${ }^{3}$ Caryn Lerman, ${ }^{1,2}$ and Daniel D. Langleben ${ }^{1,2}$ \\ ${ }^{1}$ Annenberg Public Policy Center, ${ }^{2}$ Department of Psychiatry, and ${ }^{3}$ Annenberg School for Communication, University of Pennsylvania, Philadelphia, \\ Pennsylvania 19104
}

Televised public service announcements are video ads that are a key component of public health campaigns against smoking. Understanding the neurophysiological correlates of anti-tobacco ads is an important step toward novel objective methods of their evaluation and design. In the present study, we used functional magnetic resonance imaging (fMRI) to investigate the brain and behavioral effects of the interaction between content ("argument strength," AS) and format ("message sensation value," MSV) of anti-smoking ads in humans. Seventy-one nontreatment-seeking smokers viewed a sequence of 16 high or 16 low AS ads during an fMRI scan. Dependent variables were brain $\mathrm{fMRI}$ signal, the immediate recall of the ads, the immediate change in intentions to quit smoking, and the urine levels of a major nicotine metabolite cotinine at a 1 month follow-up. Whole-brain ANOVA revealed that AS and MSV interacted in the inferior frontal, inferior parietal, and fusiform gyri; the precuneus; and the dorsomedial prefrontal cortex (dMPFC). Regression analysis showed that the activation in the dMPFC predicted the urine cotinine levels 1 month later. These results characterize the key brain regions engaged in the processing of persuasive communications and suggest that brain fMRI response to anti-smoking ads could predict subsequent smoking severity in nontreatment-seeking smokers. Our findings demonstrate the importance of the quality of content for objective ad outcomes and suggest that fMRI investigation may aid the prerelease evaluation of televised public health ads.

\section{Introduction}

Smoking is the most common preventable cause of death worldwide (WHO, 2012). Televised public service announcements (PSAs) are film ads that are the key component of anti-smoking public health campaigns. Such campaigns have had variable outcomes suggesting the need to improve methods of ad evaluation (Cummings, 1999; Sly et al., 2001; Hersey et al., 2005; Wakefield et al., 2005; Durkin et al., 2012; Emery et al., 2012). Functional magnetic resonance imaging ( $\mathrm{fMRI}$ ) has been highly informative in the study of the brain mechanisms underlying the processing of audiovisual stimuli, such as encoding of information (Gabrieli et al., 1998), feature films (Rao et al., 2007; Hasson et al., 2010; Whittingstall et al., 2010), and televised commercials (Morris et al., 2008). Recently, fMRI has been applied to the study of persuasive health messages and video ads (Langleben et al., 2009; Falk et al., 2010; Chua et al., 2011; Falk et al., 2011). In communication theories, content and format of ads are considered crit-

\footnotetext{
Received Aug. 8, 2012; revised March 6, 2013; accepted March 13, 2013.

Author contributions: J.W.L., A.A.S., K.R., J.N.C., C.L., and D.D.L. designed research; S.J.B. and D.D.L. performed research; J.W.L., A.A.S., J.N.C., and D.D.L. contributed unpublished reagents/analytic tools; A.-L.W., J.W.L., K.R., S.J.B., K.G.L., and D.D.L. analyzed data; A.-L.W., D.R.R., J.N.C., C.L., and D.D.L. wrote the paper.

The authors declare no competing financial interests.

This work was funded by the National Institute on Drug Abuse (Grant R21 DA024419).

Correspondence should be addressed to Daniel D. Langleben, Center for the Study of Addictions, 3900 Chestnut Street, Philadelphia, PA 19104. E-mail: langlebe@mail.med.upenn.edu.

DOI:10.1523/JNEUROSCI.3840-12.2013

Copyright $\odot 2013$ the authors $\quad 0270-6474 / 13 / 337420-08 \$ 15.00 / 0$
}

ical to change intentions and consequently behavior (Fishbein and Cappella, 2006). Content has been operationalized as argument strength (AS) and format as message sensation value (MSV) (Petty and Cacioppo, 1986; Kang et al., 2006; Park et al., 2007; Lee et al., 2011; Zhao et al., 2011). AS is a measure of an audience's perception of the quality and persuasiveness of ad arguments (Strasser et al., 2009; Zhao et al., 2011) and MSV is a standard aggregate measure of audio and visual features of ads, such as cuts, special effects, intense images, and music (Morgan, 2003).

Our previous study (Langleben et al., 2009) focused on format and found that ads low in MSV were better recalled, and associated with greater brain activation in the superior, middle, and orbital frontal and middle temporal gyri, and less activation in the occipitoparietal cortex, than high MSV ads. Since that study did not manipulate the AS of ads and contained no long-term behavior outcome, it could not determine the effect of content on the brain or long-term behavioral correlates of ad processing. Communication research shows that ad content is no less important to outcomes than format (Fishbein et al., 2002a; Lee et al., 2011). Indeed, communication theories (Petty and Cacioppo, 1986; Donohew et al., 1998) concur that it is the interaction between content and format that ultimately affects outcomes, but differ on whether high MSV facilitates or impedes the processing of ad content (Strasser et al., 2009). Behavioral experimental studies report content by format interactions on attention to televised ads (Geiger and Reeves, 1993), as well as smokers' attitudes and intentions toward quitting (Strasser et al., 2009). The present 
study investigated the brain and behavioral effects of content and format interactions in nontreatment-seeking smokers. We hypothesized that the brain regions mediating cognitive processing will be activated by the content and format interaction and that this activation will predict cognitive and behavioral measures of smoking, indexed by intention to quit and delayed urinary levels of the nicotine metabolite cotinine.

\section{Materials and Methods}

\section{Subjects}

Seventy-one (37 female, 38 Caucasian, 27 African American, 4 Asian, and 2 Hispanic, 4 left-handed) nontreatment-seeking participants who reported smoking an average of $14.4 \pm 7$ cigarettes per day, aged from 18 to 49 years $(30.21 \pm 9.69$ year, mean $\pm S D)$, with an average of $14 \pm 2$ years of education, were recruited by advertising. Participants gave written informed consent to participate in the protocol approved by the University of Pennsylvania Institutional Review Board. Screening exclusion criteria were (1) presence of DSM-4-TR Axis 1 psychiatric disorder (First, 2002); (2) urine drug screen (UDS) positive for illicit opioids, benzodiazepines, cannabinoids, cocaine, or methamphetamine; (3) baseline urinary cotinine levels $<50 \mathrm{ng} / \mathrm{ml}$ (SRNT Subcommittee on Biochemical Verification, 2002); (4) presence of medical or neurological disorder or treatment that may affect the cerebrovascular system; and (5) safetyrelated contraindications for MRI scanning. Once enrolled in the study, participants were randomly assigned to either high AS or low AS group.

\section{Materials and design}

One hundred ninety-nine $30 \mathrm{~s}$ long filmed anti-smoking PSAs targeting adult smokers were obtained from the Annenberg School of Communications collection (Strasser et al., 2009; Lee et al., 2011; Zhao et al., 2011). The argument quality and format of the PSAs were evaluated using perceived AS and MSV measures, respectively, (Fishbein et al., 2002b; Morgan, 2003; Strasser et al., 2009; Zhao et al., 2011). The study followed a $2 \times 2$ design, with AS as a between-subjects variable and MSV as a within-subject variable, to enable collecting the behavioral correlates (recall, intention to quit smoking, and cotinine levels) as functions of high and low AS separately.

The AS score for each PSA was generated following a previously reported procedure (Strasser et al., 2009). Briefly, explicit and implicit messages in each ad were transcribed independently by two trained raters. These transcripts were then reviewed by two different raters who chose a single statement (central argument) that best reflected the arguments in each ad (Strasser et al., 2009; Lee et al., 2011; Zhao et al., 2011). These central arguments were then rated in a survey of 387 current smokers, who were asked to rate between 8 and 12 PSAs using a questionnaire with 11 questions (5-point scale, 1 = strongly disagree, $5=$ strongly agree). A balanced design was used so that each ad was rated by an average of 38 smokers. The AS scores for each ad were created by summing each rater's responses to the 11 questions, then an overall AS score for each ad was created by taking the mean of the individual ratings for that ad (Strasser et al., 2009; Zhao et al., 2011).

MSV is a validated aggregate measure of audio and visual format features of PSAs. MSV variables are visual (cuts, edits, special effects, motion change, vivid coloring), audio (sound saturation, sound level, music and voices), and narrative (cuts, edits, and surprise endings). (Morgan, 2003; Langleben et al., 2009; Strasser et al., 2009). Three trained raters independently viewed and rated each ad for MSV parameters. Inter-rater reliability of MSV scoring between pairs of raters was high (Kendall's tau = $0.906, p<0.001)$.

Finally, from the available 199 ads rated for MSV and AS, we selected 32 ads exceeding one SD from the mean on each of the two dimensions (AS and MSV), thus yielding four ad categories: High AS/High MSV, High AS/Low MSV, Low AS/High MSV, and Low AS/Low MSV. Each category comprised eight videos. Participants were randomly assigned to either the high AS group, which viewed 16 high AS PSAs ( 8 High AS/High MSV and 8 High AS/Low MSV), or the low AS group, which viewed the 16 low AS PSAs (8 Low AS/High MSV and 8 Low AS/Low MSV). The topics of the central arguments of the 32 PSAs were: "Smoking causes disease and/or death" (15), "Smoking is aversive to others" (9), "Smoking will harm your baby or child" (6), "Smoking harms others" (1), "Not smoking has health or other benefits" (5), and "There are ways to help you quit" (2). Six ads had two topics. The number of ads that contained smoking cues was balanced between the groups: Six of 16 PSAs in the high AS group and 6 of 16 PSAs in the low AS group contained images of smoking.

PSA video task. Sixteen PSAs were presented in a random order and separated by $16 \mathrm{~s}$ interstimulus intervals (ISI; gray cross-hair on a homogenous black background). An additional $16 \mathrm{~s}$ baseline period with the same fixation point was presented at the beginning of the task. Each PSA was $30 \mathrm{~s}$ long and was presented only once. The task duration was 12 min and $36 \mathrm{~s}$.

Frame recognition task. This task tested the memorability of the PSAs (Rossiter and Silberstein, 2001; Langleben et al., 2009) by measuring the correct recognition of frames extracted from PSAs viewed in the video task. Participants were asked to respond with a "Yes" or "No" to the question "Have you seen this ad?" displayed on top of each frame, using a single axis scroll wheel (FORP; Current Design). Frame recognition task (FRT) contained a total of 96 still frames, 48 were targets that were extracted from 16 PSAs used in the PSA video task (three frames from each PSA, one from each 10 s segment of each 30 s PSA), and 48 were foils that were drawn from comparable anti-tobacco PSAs not shown in this study. All frames were presented in a pseudorandom order (Dale, 1999) with variable ISIs ranging from 1.5 to $9.5 \mathrm{~s}$ in duration. Each frame was displayed once, for $2.5 \mathrm{~s}$. The task duration was $10 \mathrm{~min}$ and $6 \mathrm{~s}$.

Both tasks were programmed in the Presentation (Neurobehavioral Systems) stimulus presentation package. Stimuli were delivered through a rear projector system (Epson American) that was viewed through a mirror mounted on the MRI scanner head coil. The video soundtrack was delivered through Silent Scan 2100 MRI-compatible headphones (Avotec).

\section{Procedure}

Baseline assessments. Participants were screened for eligibility for fMRI, demographics, and handedness (Oldfield, 1971). One hour before the fMRI session, participants provided urine samples for baseline cotinine levels and UDS (Reditest; Redwood Toxicology Labs), and completed the Fagerstrom Test of Nicotine Dependence (FTND), the average number of cigarettes per day (Sobell and Sobell, 1992), and baseline Intention to Quit Smoking (IQS) assessment (Gibbons et al., 1998; Fishbein et al., 2001a). Cotinine levels were measured using the HPLC tandem mass spectrometry system (Agilent Technologies) with a limit of detection of 2 $\mathrm{ng} / \mathrm{ml}$. FTND is a six-item, self-report measure with a range of $0-10$, where higher scores reflect greater nicotine dependence (Heatherton et al., 1991). The FTND has good internal consistency and high test-retest reliability (Pomerleau et al., 1994). IQS is a two-item self-report measure of likelihood and certainty of one's quitting smoking in the next 12 months, ranging from 1 (not likely) to 4 (very likely).

The study was comprised of an MRI session and a follow-up session 1 month later. Participants were randomly assigned to either the high AS group who watched High AS/High MSV and High AS/Low MSV PSAs, or the low AS group who watched Low AS/High MSV and Low AS/Low MSV PSAs. After completion of the baseline assessments and 30-45 min before the onset of the fMRI session, participants were escorted outdoors to smoke one of their own cigarettes under observation. All participants took the opportunity to smoke and consumed no more than one cigarette. Before the FRT task started, participants were instructed to attend to the video ads, and were told that the video task will be followed by a memory test of how well they remembered the ads. IQS was repeated immediately after the MRI session. At the follow-up session approximately 1 month later $(33 \pm 12 \mathrm{~d}$, mean $\pm \mathrm{SD})$, a repeat urine sample for cotinine level was collected, and self-reported average number of cigarettes per day was recorded.

\section{Image acquisition}

Siemens Tim Trio $3 \mathrm{~T}$ (Erlangen) system and 32-channel head coil were used for the MRI imaging. blood oxygenation level-dependent (BOLD) fMRI (Bandettini et al., 1992; Kwong et al., 1992) was performed, using a 
whole-brain, single-shot gradient-echo echoplanar sequence with the following parameters: $\mathrm{TR} / \mathrm{TE}=2000 / 30 \mathrm{~ms}, \mathrm{FOV}=220 \mathrm{~mm}$, matrix $=$ $64 \times 64$, slice thickness/gap $=3.4 / 0 \mathrm{~mm}$, 32 slices, effective voxel resolution of $3.4 \times 3.4 \times 3.4 \mathrm{~mm}$. After BOLD fMRI, $5 \mathrm{~min}$ MPRAGE T1-weighted image $(\mathrm{TR} / \mathrm{TE}=1630 / 3.87 \mathrm{~ms}, \mathrm{FOV}=250 \mathrm{~mm}$, matrix $=$ $256 \times 192$, effective voxel resolution of $1 \times 1 \times 1 \mathrm{~mm}$ ) was acquired for anatomic overlays of functional data and spatial normalization (Lancaster et al., 2000). An oblique acquisition, oriented along the anterior commissure-posterior commissure line allowed coverage of the entire brain with the exception of the lower cerebellum.

Behavioral and imaging data attrition and quality assessment A total of eight datasets were excluded from the final analysis: three participants whose baseline cotinine levels were $<50 \mathrm{ng} / \mathrm{ml}$ (SRNT Subcommittee on Biochemical Verification, 2002); two participants whose performance on the FRT task was poor $(\operatorname{Pr}<0)$; three participants whose BOLD fMRI signal-to-noise ratio (SNR) was poor and/or had excessive $(\approx 0.23 \mathrm{~mm},>2$ SDs from the mean) head motion, expressed in temporal SNR (tSNR), and the relative volume-to-volume displacement for all subjects. Thus, data from 33 subjects in the high AS group and 30 subjects in the low AS group were included in the final analyses. The follow-up urine sample for cotinine level was obtained from 52 participants (28 in high and 24 in the low AS group) who returned for the follow-up session.

\section{Behavioral data analysis}

Statistical analyses were performed using the IBM Statistical Package of the Social Science (IBM SPSS version19). Subjects' performance on the FRT was evaluated using the Discrimination Index, $\operatorname{Pr}=Z_{\text {Correct target recognition }}-Z_{\text {False alarms }}$, which reflects how well one could correctly distinguish targets from foils (Snodgrass and Corwin, 1988). Participants whose Pr was $\leq 0$ may have been responding at a chance level and were excluded from further analysis. Subjects' tendency to respond "Yes" or "No" under uncertainty was evaluated using the Response Bias measure, $\mathrm{Br}=-0.5\left(\mathrm{Z}_{\text {Correct target recognition }}+\mathrm{Z}_{\text {False alarm }}\right) . \mathrm{Br}=0$ indicates no bias, $\mathrm{Br}<0$ indicates liberal bias (i.e., tendency of saying "Yes" when uncertain), $\mathrm{Br}>0$ indicates conservative bias (i.e., tendency of saying "No" when uncertain). Change scores for IQS were calculated as the difference in scores before and after fMRI session ( $\Delta \mathrm{IQS})$. Independent-sample $t$ tests were used to compare baseline parameters of the high and low AS groups, including FTND, IQS scores, average number of cigarettes per day, cotinine levels, ages and educational levels. A two-way repeated-measures ANOVA was applied to Pr, to assess the main effects of the within-subject variable "MSV" (two levels: high MSV vs low MSV) and the between-subject variable "AS group" (two levels: high AS vs low AS), as well as their possible interaction. Partial correlation was applied to examine the relation between $\Delta I Q S$ and cotinine levels at follow-up, controlling for baseline.

\section{Functional imaging data analysis}

BOLD time series data were preprocessed and analyzed by standard procedures using the fMRI Expert Analysis Tool (FEAT; version 5.98) of FSL (FMRIB's Software Library). Single-subject preprocessing included nonbrain removal using BET (Smith, 2002) slice time correction, motion correction to the median image using MCFLIRT (Jenkinson et al., 2002), high-pass temporal filtering (138 s), spatial smoothing using a Gaussian kernel (6 mm full-width at half-maximum, isotropic), and mean-based intensity normalization of all volumes using the same multiplicative factor. The median functional volume was coregistered to the anatomical T1-weighted structural volume and then transformed into the standard anatomical space (Montreal Neurological Institute (MNI) T1 template) using FLIRT (Jenkinson and Smith, 2001; Jenkinson et al., 2002). Transformation parameters were later applied to all statistical contrast maps for group-level analyses.

The primary variable was mean percentage BOLD signal change. Subject-level statistical analyses were performed voxelwise using FILM (FMRIB's Improved General Linear Model) with local autocorrelation correction (Woolrich et al., 2001). Two condition events (high MSV, low MSV) were modeled using a canonical hemodynamic response function. Six rigid body motion correction parameters were included as nuisance covariates and the rest periods (fixation point) were treated as the baseline. Image analysis was completed for each individual in subject space,
Table 1. Summary of behavioral measures

\begin{tabular}{lcc}
\hline & High AS group & Low AS group \\
\hline Baseline & & \\
$\quad$ Race & 20 Cau, 10 AA, 3 Asian & 17 Cau, 12 AA, 1 Asian \\
Gender & $15 \mathrm{M}, 18 \mathrm{~F}$ & $16 \mathrm{M}, 14 \mathrm{~F}$ \\
Age (years) & $29.03 \pm 1.56$ & $30.20 \pm 1.89$ \\
Education level (years) & $14.03 \pm 0.33$ & $14.32 \pm 0.35$ \\
Cotinine (ng/ml) & $1517.82 \pm 378.91$ & $1392.90 \pm 216.11$ \\
IQS & $2.45 \pm 0.13$ & $2.60 \pm 0.13$ \\
FTND & $4.48 \pm 0.43$ & $4.43 \pm 0.44$ \\
$\quad$ Cigarettes per day & $16.15 \pm 1.01$ & $14.97 \pm 1.03$ \\
Immediately after MRI & & \\
$\quad$ IQS & $2.74 \pm 0.14$ & $2.63 \pm 0.12$ \\
One month later & & \\
$\quad$ Cotinine (ng/ml) & $1100.89 \pm 216.89$ & $1565.50 \pm 290.82$ \\
Cigarettes per day & $13.93 \pm 1.19$ & $14.17 \pm 1.69$ \\
\hline
\end{tabular}

Cau, Caucasian; AA, African American.

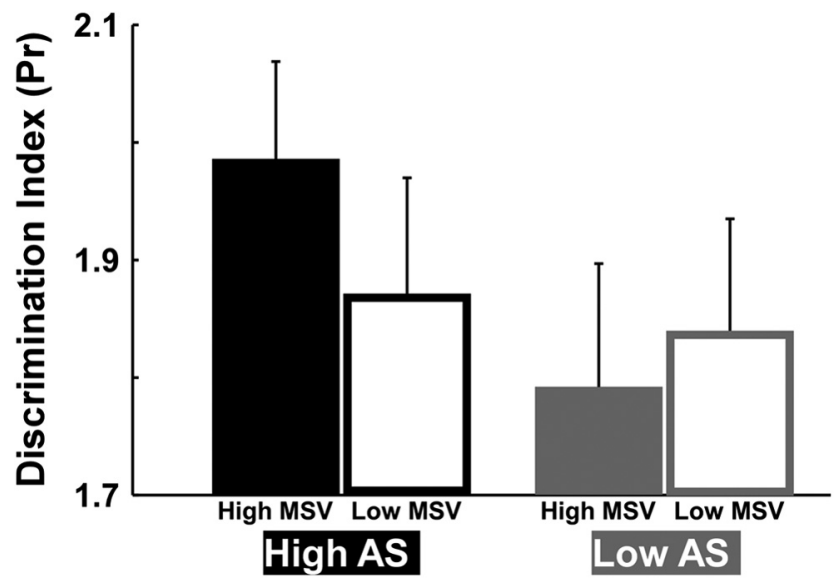

Figure 1. Performance of the Frame Recognition Task. $y$-axis: discrimination index (Pr). $x$-axis: High AS and Low AS group. AS by MSV interaction is significant $(p=0.05)$. Error bars indicate SEM.

Table 2. Brain regions associated with AS by MSV interaction

\begin{tabular}{lllrlrrr}
\hline Region $^{\mathrm{a}}$ & Hemisphere & $\mathrm{BA}^{\mathrm{b}}$ & Size $^{\mathrm{c}}$ & Z-MAX $^{\mathrm{d}}$ & \multicolumn{1}{l}{$X^{\mathrm{e}}$} & $Y^{\mathrm{e}}$ & $Z^{\mathrm{e}}$ \\
\hline Inferior parietal lobule & $\mathrm{L}$ & 40 & 4637 & 7.6 & 36 & -44 & 50 \\
Inferior parietal lobule & $\mathrm{R}$ & 40 & 3975 & 7.37 & 34 & -41 & 42 \\
Fusiform gyrus & $\mathrm{L}$ & 37 & 922 & 5.68 & -55 & -65 & -9 \\
Inferior frontal gyrus & $\mathrm{L}$ & 44 & 3101 & 6.09 & -38 & 3 & 20 \\
Precuneus & $\mathrm{R}$ & 7 & 1458 & 4.36 & 8 & -46 & 50 \\
Medial frontal gyrus & $\mathrm{R}$ & 8 & 1055 & 5.24 & 22 & 31 & 48
\end{tabular}

Location of the clusters and the local maxima of BOLD fMRI signal change.

a $Z \geq 3.1$ cluster corrected at $p<0.001$.

'Brodmann's area.

Voxels.

dZ-MAX values represent peak activation for the cluster.

'Talairach (1988) coordinates.

and resulting contrast maps of parameter estimates were spatially normalized as described above.

\section{Voxelwise whole-brain analysis}

Parameter estimates were entered into an AS (high AS vs low AS) by MSV (high MSV vs low MSV) ANOVA treating subjects as random effects variable. Resulting Z (Gaussianized $F$ ) statistic maps of AS group by MSV interaction, as well as main effects of AS and MSV, were cluster corrected at $Z \geq 3.1$ using theory of Gaussian Random Fields (Beckmann and Smith, 2004). Anatomic assignment of clusters was based on the peak $z$-score within the cluster using the Talairach Daemon Database confirmed by visual inspection. Mean scaled $\beta$ coefficients (percentage 

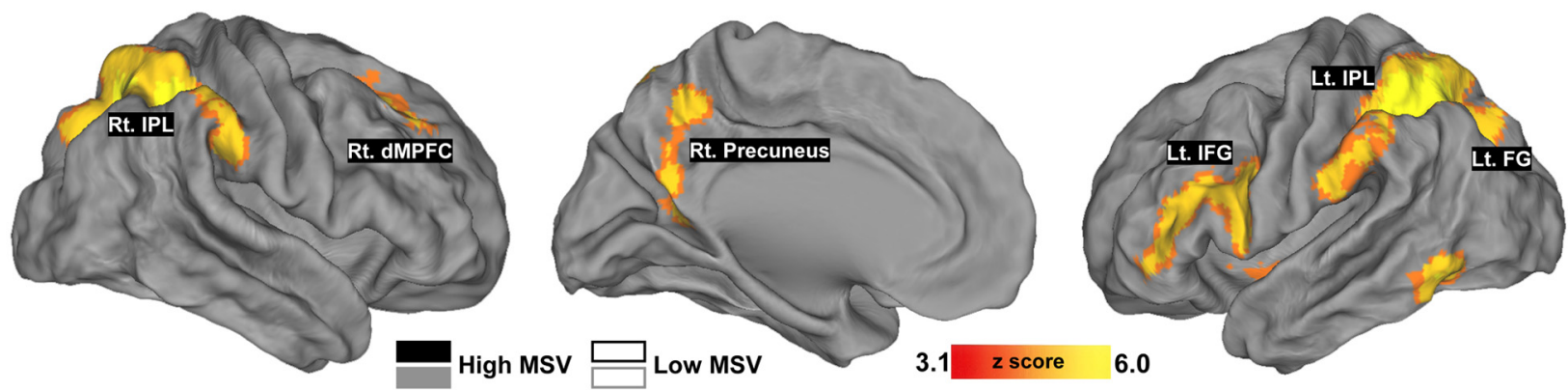

Rt. IPL

Rt. dMPFC

Rt. Precuneus

Lt. IFG

Lt. IPL

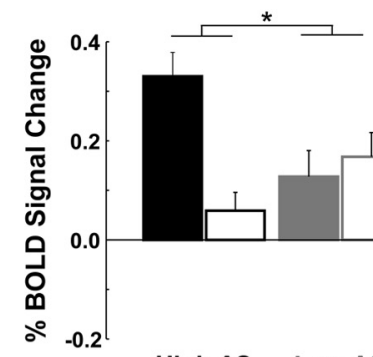

High AS Low AS

High AS Low AS

High AS Low AS

High AS Low AS

High AS Low AS

Figure 2. Brain regions associated with AS by MSV interaction and percentage BOLD signal change in these regions. Images: brain $\mathrm{fMRI}$ activation maps associated with AS by MSV interaction in the bilateral IPL (left IPL, $x=36, y=-44, z=50$; right IPL, $x=34, y=-41, z=42)$, the left IFG $(x=-38, y=3, z=20)$, left FG $(x=-55, y=-65, z=-9)$, right dMPFC ( $x=22$, $y=-31, z=48)$, and right precuneus $(x=8, y=-46, z=50)$. Surface visualization (CARET; http://brainvis.wustl.edu) represents voxelwise $z$-statistical maps thresholded at $z=3.1$ (cluster corrected $p<0.001)$. Bar charts: BOLD signal change in the brain regions associated with AS by MSV interaction. $y$-axis: percentage BOLD signal change. $x$-axis (from left to right): high AS and low AS groups. Error bars indicate SEM. Significant AS by MSV interactions $(p<0.05)$ in each brain region are represented by asterisks.

BOLD signal change) from each significant cluster in the interaction map were extracted for graphic examination and further statistical testing.

\section{Correlation analysis}

Linear regression analysis was applied to examine whether the neural response to PSAs (percentage BOLD signal change) in brain regions associated with the AS by MSV interaction predicted IQS change immediately after the fMRI session, controlling for baseline IQS scores and group (high/low AS). Also, linear regression analysis was applied to examine whether the neural response to PSAs (percentage BOLD signal change) in brain regions associated with AS by MSV interaction predicted urinary cotinine levels at the 1 month follow-up, controlling for baseline levels for group (high/low AS). To test the relationship between cotinine levels and brain response, we used percentage BOLD signal change extracted from the regions of interest (ROIs) identified by the preceding whole-brain analysis. Such "off-line" correlation analysis has been used in the prior fMRI studies of PSA (Chua et al., 2009, 2011; Langleben et al., 2009). By limiting the number of statistical tests to the few ROIs defined by the preceding whole-brain analysis, this approach offers a more appropriate level of control for Type 1 errors than the whole brain correlation (Poldrack, 2007).

\section{Results}

\section{Behavioral results}

Participants' behavioral measures at baseline, immediately after MRI and at 1 month follow-up were summarized in Table 1. Baseline FTND score was $4.46 \pm 2.40$, baseline cotinine levels were $1458.33 \pm 1762 \mathrm{ng} / \mathrm{ml}$, and baseline IQS was $2.52 \pm 0.73$. The high and low AS groups did not differ in age $\left(t_{(61)}=-0.48\right.$, $p=0.63)$, educational level $\left(t_{(61)}=-0.59, p=0.56\right)$, baseline smoking severity (FTND $t_{(61)}=0.08, p=0.93$, cotinine levels $t_{(61)}=0.28, p=0.78$, average number of cigarettes per day $t_{(61)}=$ $0.82, p=0.41)$ or IQS scores $\left(t_{(61)}=-0.079, p=0.44\right)$.

Two-way repeated-measures ANOVA revealed a significant interaction between MSV and AS group $\left(F_{(1,61)}=3.90, p=0.05\right)$ on ad frame recognition performance (Fig. 1), but no main effect of
$\operatorname{MSV}\left(F_{(1,61)}=1.16, p=0.29\right)$ or AS $\operatorname{group}\left(F_{(1,61)}=1.36, p=\right.$ $0.25)$. High MSV better facilitated frame recognition than low MSV $\left(t_{(32)}=2.31, p=0.03\right)$ if the PSA AS was strong, while MSV strength had no differential effect on frame recognition $\left(t_{(29)}=-0.594, p=\right.$ 0.557 ) if the PSA AS was weak. Subjects tended to respond liberally when they recalled frames from the Low AS/Low MSV PSAs $(\mathrm{Br}=$ -0.133 ), and conservatively to the frames extracted from other AS/ MSV combinations $(\mathrm{Br}=0.068,0.004,0.089)$.

The IQS immediately after PSA exposure was significantly higher than baseline $\left(t_{(62)}=-2.390, p=0.020\right)$. The change in the IQS $(\Delta \mathrm{IQS})$ after the PSA video task was marginally larger in the high AS group $(0.288 \pm 0.097)$ than in the low AS group $(0.033 \pm 0.096),\left(t_{(61)}=1.858, p=0.068\right)$. Furthermore, partial correlation revealed that $\Delta \mathrm{IQS}$ was negatively correlated with cotinine levels at follow-up $(r=-0.342, p=0.014)$.

\section{Functional imaging results}

A whole-brain $2 \times 2$ ANOVA revealed a significant interaction between AS and MSV ( $Z \geq 3.1$, corrected for multiple comparison at $p<0.001$ ) (Table 2). The interaction of AS and MSV was observed in the bilateral inferior parietal lobule (IPL), left inferior frontal gyrus (IFG; peak in Brodmann area (BA) 44-47, extending to BA 10 and 13), left fusiform gyrus (FG), the right dorsomedial prefrontal cortex (dMPFC; peak in BA 8, extending to BA 9 and 32), and the precuneus (peak in BA 7, extending to BA 32 and 31) (Fig. 2). There were also significant main effects of AS and $\operatorname{MSV}(Z \geq 3.1$, corrected for multiple comparisons at $p<0.001)$ (Table 3).

\section{Correlation results}

Greater activation in the precuneus during PSA viewing marginally predicted greater IQS $(\beta=0.167, p=0.061)$. In addition, a linear regression analysis showed that follow-up cotinine levels 
Table 3. Brain regions associated with main effects of AS and MSV

\begin{tabular}{|c|c|c|c|c|c|c|c|}
\hline$\overline{\text { Region }^{\mathrm{a}}}$ & Hemisphere & $\mathrm{BA}^{\mathrm{b}}$ & Size $^{c}$ & Z-MAX & $x^{\mathrm{e}}$ & $y^{\mathrm{e}}$ & $Z^{\mathrm{e}}$ \\
\hline \multicolumn{8}{|l|}{ Main effect of AS } \\
\hline Lingual G. & $\mathrm{R}$ & 18 & 15246 & 8.59 & 23 & -71 & -10 \\
\hline Precuneus & L & 7 & & 8.25 & -5 & -57 & 47 \\
\hline Precuneus & $\mathrm{R}$ & 7 & & 8.35 & 14 & -64 & 39 \\
\hline Cuneus & $\mathrm{R}$ & 7 & & 8.26 & 25 & -77 & 31 \\
\hline Middle Occipital G. & $\mathrm{R}$ & 19 & & 5.90 & 29 & -94 & 21 \\
\hline Superior Temporal G. & L & 42 & & 8.37 & -62 & -22 & 11 \\
\hline Middle Temporal G. & $\mathrm{R}$ & 21 & 6267 & 7.47 & 58 & 7 & -14 \\
\hline Middle Temporal G. & $\mathrm{R}$ & 22 & & 8.45 & 48 & -39 & -1 \\
\hline Parahippocampal G. & $\mathrm{R}$ & 19 & & 8.40 & 42 & -41 & -1 \\
\hline Precuneus & L & 7 & & 7.69 & -20 & -58 & 30 \\
\hline Superior Temporal G. & $\mathrm{R}$ & 42 & & 7.22 & 63 & -31 & 16 \\
\hline Precentral G. & $\mathrm{R}$ & 4 & 5900 & 7.52 & 37 & -16 & 48 \\
\hline Cingulate $\mathrm{G}$. & L & 24 & & 6.85 & 1 & 0 & 45 \\
\hline Precentral G. & $\mathrm{R}$ & 6 & & 6.52 & 21 & -15 & 64 \\
\hline Superior Frontal G. & $\mathrm{R}$ & 10 & 1977 & 6.52 & 22 & 51 & 27 \\
\hline Middle Frontal G. & $\mathrm{R}$ & 8 & & 6.10 & 33 & 38 & 40 \\
\hline Superior Frontal G. & $\mathrm{R}$ & 9 & & 4.97 & 29 & 56 & 34 \\
\hline Supramarginal G. & $\mathrm{R}$ & 40 & 1498 & 7.54 & 48 & -45 & 30 \\
\hline Inferior Parietal Lobule & $\mathrm{R}$ & 40 & & 7.40 & 52 & -47 & 26 \\
\hline Inferior Temporal G. & $\mathrm{R}$ & 20 & & 6.87 & 57 & -60 & -11 \\
\hline Insula & $\mathrm{R}$ & 13 & & 6.78 & 37 & -37 & 21 \\
\hline Middle Temporal G. & $\mathrm{R}$ & 39 & & 6.20 & 59 & -57 & 13 \\
\hline Superior Temporal G. & $\mathrm{R}$ & 22 & & 5.98 & 35 & -48 & 24 \\
\hline Parahippocampal G. & $\mathrm{R}$ & $\mathrm{N} / \mathrm{A}$ & 1269 & 5.56 & 22 & -6 & -10 \\
\hline Inferior Frontal G. & $\mathrm{R}$ & 47 & & 5.34 & 24 & 34 & -7 \\
\hline Hypothalamus & $\mathrm{R}$ & N/A & & 5.18 & 5 & -6 & -4 \\
\hline Parahippocampal G. & $\mathrm{R}$ & 34 & & 4.19 & 12 & -13 & -19 \\
\hline Lentiform Nucleus & $\mathrm{R}$ & $\mathrm{N} / \mathrm{A}$ & & 4.17 & 18 & 11 & -7 \\
\hline Inferior Frontal G. & $\mathrm{R}$ & 9 & 1088 & 5.91 & 52 & 5 & 27 \\
\hline Inferior Frontal G. & $\mathrm{R}$ & 44 & & 5.73 & 58 & 17 & 16 \\
\hline Middle Frontal G. & $\mathrm{R}$ & 6 & & 5.54 & 42 & -3 & 50 \\
\hline Precentral G. & $\mathrm{R}$ & 6 & & 5.43 & 46 & -3 & 51 \\
\hline Inferior Frontal G. & $\mathrm{R}$ & 46 & & 4.68 & 56 & 29 & \\
\hline Precentral G. & L & 6 & 1024 & 7.16 & -33 & 0 & 25 \\
\hline Middle Frontal G. & $\mathrm{L}$ & 6 & & 6.34 & -41 & 4 & 43 \\
\hline Precentral G. & L & 9 & & 5.87 & -35 & 5 & 40 \\
\hline Middle Frontal G. & L & 6 & & 5.65 & -41 & 6 & 52 \\
\hline Middle Frontal G. & L & 9 & & 5.15 & -52 & 22 & 33 \\
\hline \multicolumn{8}{|l|}{ Main effect of MSV } \\
\hline Fusiform G. & $\mathrm{R}$ & 37 & 39321 & 8.21 & 29 & -42 & -16 \\
\hline Cuneus & $\mathrm{L}$ & 18 & & 8.15 & -22 & -82 & 29 \\
\hline Middle Occipital G. & L & 18 & & 8.18 & -18 & -89 & 15 \\
\hline Middle Occipital G. & $\mathrm{L}$ & 19 & & 8.15 & -24 & -81 & 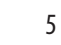 \\
\hline Cuneus & L & 17 & & 8.21 & 16 & -83 & \\
\hline Lingual G. & $\mathrm{L}$ & $N / A$ & & 8.21 & -32 & -73 & \\
\hline Medial Frontal G. & $\mathrm{L}$ & 6 & 2973 & 6.04 & -1 & -12 & 59 \\
\hline Superior Frontal G. & L & 6 & & 5.99 & -5 & -1 & 63 \\
\hline Medial Frontal G. & L & 6 & & 5.45 & -7 & 3 & 56 \\
\hline Cingulate G. & $\mathrm{L}$ & 32 & & 4.57 & -9 & 12 & 42 \\
\hline Precentral G. & $\mathrm{L}$ & 4 & & 4.56 & 21 & -24 & 67 \\
\hline Cingulate G. & $\mathrm{L}$ & 24 & & 4.56 & -7 & -6 & 48 \\
\hline Middle Temporal G. & $\mathrm{L}$ & 21 & 2403 & 7.17 & -54 & -28 & -8 \\
\hline Parahippocampal G. & $\mathrm{L}$ & 19 & & 5.98 & -41 & -38 & -1 \\
\hline Caudate & L & $\mathrm{N} / \mathrm{A}$ & & 4.23 & -18 & -36 & 15 \\
\hline Inferior Parietal Lobule & $\mathrm{L}$ & 40 & 1505 & 6.96 & -56 & -28 & 23 \\
\hline Inferior Frontal G. & $\mathrm{L}$ & 44 & 1147 & 5.69 & -50 & 16 & 11 \\
\hline
\end{tabular}

Location of the clusters and the local maxima of BOLD fMRI signal change.

a $Z \geq 3.1$ cluster corrected at $p<0.001$.

bBrodmann's area.

'Voxels.

dZ-MAX values represent peak activation for the cluster.

eTalairach (1988) coordinates. were significantly lower in the high AS group than the low AS group ( $\beta=0.227, p=0.021)$, and among the subjects with greater dMPFC activation $(\beta=-0.201, p=0.043)$ (Fig. 3, right; $r=-0.55)$.

To determine whether the dMPFC mediated the relationship between the AS and cotinine levels, we performed a mediation analysis with $\mathrm{dMPFC}$ activation as an intervening variable between AS and the follow-up cotinine level and with baseline cotinine level as a covariate. The coefficient for the total effect of AS on cotinine, ignoring dMPFC activation, was $0.21(p=0.03)$. When dMPFC activation was included in the model, the regression coefficient for AS was 0.23 ( $p=0.02$ ), so the effect remained about the same. This was due to the fact that AS did not have a significant effect on dMPFC activation $(p=0.32)$. Thus, though both AS and AMPFC activation affected the cotinine outcome, the AS effect on cotinine outcome was not explained by the dMPFC activation.

\section{Discussion}

This is the first longitudinal investigation of the cognitive, behavioral, and neurophysiological response to the content and format of televised anti-smoking ads. At the cognitive level, we found that the effect of MSV on immediate recall depended on the AS of the ad. Higher MSV in ads with strong arguments produced better frame recognition, but made no difference when combined with a weak argument. In addition, greater changes in intention to quit smoking were associated with lower urine cotinine levels at follow-up. At the brain level, we characterized regions activated by the interaction of content and format and thus critical to the processing of persuasive messages. These included the bilateral IPL, left FG, IFG, right dMPFC, and the precuneus (Fig. 2). Of these regions, the activation in the dMPFC predicted sustained reduction in urinary cotinine levels at a 1 month follow-up.

The bilateral occipitoparietal clusters showed symmetrical activations (Fig. 2), largest in the High AS/High MSV condition and no difference between high and low MSV in the low AS group. This pattern mirrored the short-term recognition of the ads (Fig. 1), consistent with the role of the occipitoparietal cortex in sustained stimulus-driven (exogenous) attention (Johnson and $\mathrm{Za}$ torre, 2006; Indovina and Macaluso, 2007). This finding extends our prior observation (Langleben et al., 2009) that the strength of the audiovisual format of an ad is the primary driver of occipitoparietal (IPL and FG) activation. The fact that occipitoparietal regions were not sensitive to MSV under the low AS condition fine-tunes this earlier observation and suggests that strong audiovisual format is only effective in attracting visual attention in ads with strong arguments.

The left-sided inferior prefrontal activation encompassed the IFG (Fig. 2) and extended to the prefrontal associative cortices and the anterior insula. Inferior frontal activation is associated with behavioral regulation and control processes (Aron, 2007) as well as cognitive processing. Specifically, the left inferior prefrontal cortex contains language and association areas that are involved in semantic ("deep") processing (Gabrieli et al., 1998), integration, and sentence comprehension (Meltzer et al., 2010; Zhu et al., 2012). Thus left inferior frontal activation could be interpreted as an indicator of intensity of processing (Demb et al., 1995; Stephenson et al., 2001).

The dMPFC was less active than baseline ("deactivated") in all ad categories, with greatest deactivation associated with the High AS/High MSV ads. An influential review and meta-analysis describes $\mathrm{dMPFC}$ as a region operating in a "dynamic functional 


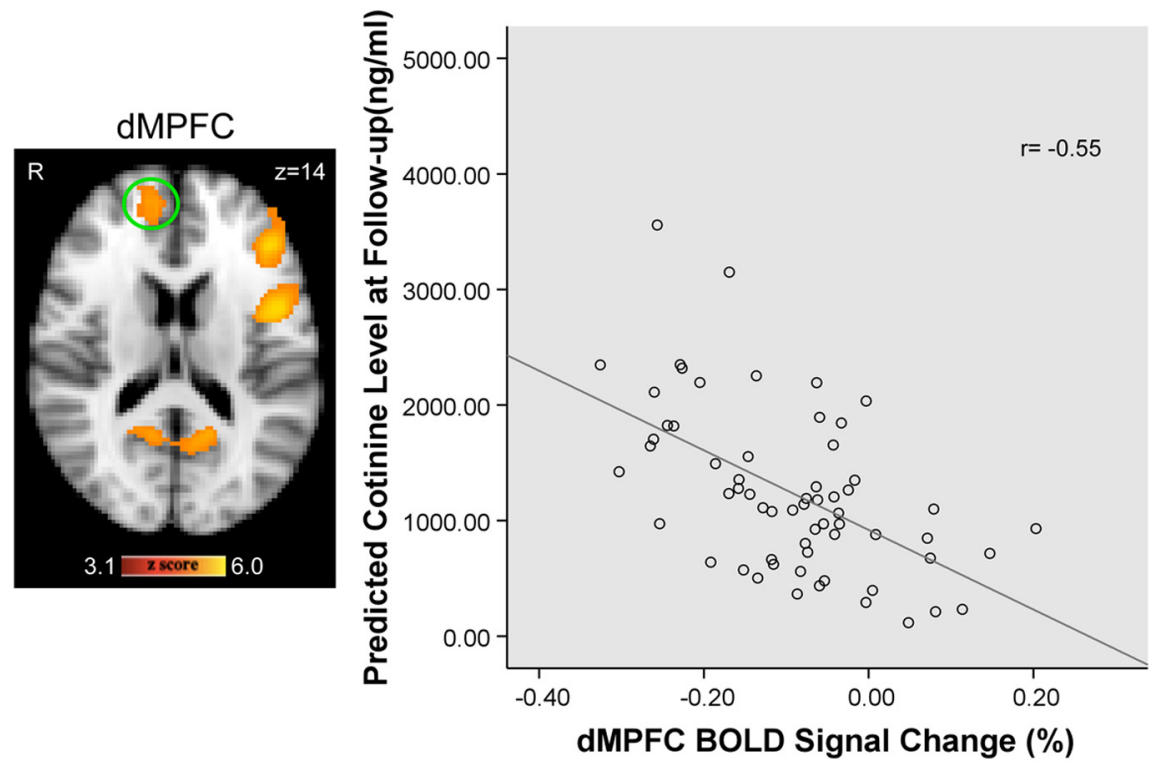

Figure 3. Left, dMPFC activation associated with AS by MSV interaction. Statistical map (yellow-red scale) is displayed over the MNI brain template and thresholded at $z=3.1$ (cluster corrected at $p<0.001$ ). Right, Correlation between percentage BOLD signal change in dMPFC and predicted cotinine levels at 1 month follow-up, adjusting for the baseline cotinine levels and AS groups.

range," activated during tasks that involve self-referential cognition and internally focused attention (Buckner and Carroll, 2007), and deactivated during tasks that involve externally focused attention (Gusnard and Raichle, 2001). Fox et al. (2005) described MPFC as a task-negative region that is "anticorrelated" to the "task-positive" regions such as the IPL, which actively mediate focused attention (Gusnard et al., 2001; Buckner and Carroll, 2007; Toro et al., 2008; Vincent et al., 2008). Specifically, concurrent deactivation of AMPFC and activation of IPL has been reported during processing of self-relevant speech (Jardri et al., 2007). In addition to deactivation during exogenous attention, MPFC is activated by thinking about one's intention and consequential actions (den Ouden et al., 2005; Buckner and Carroll, 2007). Burgess et al. (2003) propose that dMPFC plays a role in maintaining an intention to act while performing a concurrent task, which requires withdrawing cognitive resources from the ongoing stimuli. Thus, the fMRI signal changes we observed in the dMPFC could well result from the two anti-correlated processes concurrently engaged by ad viewing: deactivation due to exogenous attention and activation due to self-referential processes such as thinking about one's intentions. Indeed, we found that while the greatest $\mathrm{dMPFC}$ deactivation was during viewing of the High AS/High MSV ads, it was dMPFC activation that predicted the long-term reduction in urine cotinine. This suggests that of the four ad categories, the High AS/High MSV ads engaged exogenous attention most but the self-referential cognition and intention formation least.

Precuneus was also deactivated, with the greatest deactivation in the Low AS/Low MSV category. Similarly to dMPFC, precuneus is engaged in a range of cognitive functions, including deactivation during increased exogenous attention demands (Cavanna and Trimble, 2006; Zhang and Li, 2012). Although both precuneus and MPFC are parts of the resting state network (Gusnard et al., 2001; Raichle et al., 2001; Northoff and Bermpohl, 2004), incongruence in the direction of activation between these two regions is not uncommon (Laird et al., 2009; Dastjerdi et al., 2011; Gilbert et al., 2012). dMPFC activation without cor- responding precuneus activation was present in up to half of $72 \mathrm{fMRI}$ and PET studies of emotion and cognition (Phan et al., 2002) and a dissociation between precuneus and dMPFC activation was observed during active self-referential activities (Whitfield-Gabrieli et al., 2011). Thus, inconsistency in the direction of activation of $\mathrm{dMPFC}$ and precuneus could be expected with complex, emotionally charged, self-referential stimuli such as our anti-smoking ads.

At the behavioral level, we found that the intensity of ad format (MSV) only influenced recognition when paired with the more persuasive ads. Intensity of ad format made no difference on recognition when presenting a weak argument. Also, we found an increase in the intention to quit smoking $(\Delta \mathrm{IQS})$ immediately after ad exposure, which is in agreement with prior studies (Park et al., 2007; Updegraff et al., 2007; Strasser et al., 2009; Lee et al., 2011). According to the theory of reasoned action (Fishbein, 2000, 2001a,b), a change in intentions is important for change in behavior. In the context of smoking prevention research, Norman et al. (1999) confirmed that IQS ( $\Delta$ IQS) predicted the number of quit attempts and length of abstinence at 6 month follow-up. Similarly, we found a significant negative correlation between $\triangle \mathrm{IQS}$ and cotinine levels at follow-up.

Our data show that dMPFC, IPL, and left IFG are the brain areas integrating the content and format of persuasive ads. The finding that $\mathrm{dMPFC}$ activation predicted a positive behavioral outcome (i.e., lower cotinine levels a month later) has potential translational significance. Cotinine levels are considered the gold standard measure of nicotine intake for the preceding 3-5 $\mathrm{d}$ and are an objective measure of sustained smoking behavior in nontreatment-seeking smokers (SRNT Subcommittee on Biochemical Verification, 2002). Our findings are consistent with previous reports showing that $\mathrm{MMPFC}$ activation associated with the level of personal relatedness (tailoring) of anti-tobacco messages predicts smoking cessation treatment outcomes (Chua et al., 2009, 2011). Despite the use of different populations of smokers (treatment seeking vs nontreatment seeking) and different stimuli (persuasive statements vs videos), Chua et al. $(2009,2011)$ and the current study point to a similar conclusion: dMPFC activation predicts long-term behavior. This suggests that the predictive value of $\mathrm{dMPFC}$ could generalize to all smokers and formats of persuasive communications.

Our findings should be interpreted with several caveats. First, we evaluated average brain response over the entire length of real-life ads. Future research is required to investigate the frameby-frame brain response to the changes in ad content and format (Hasson et al., 2010). Second, MSV was a within-subject variable, allowing us to assess its brain effects but not the delayed behavioral outcomes. A four-cell design, with both content and format as between-group variables could be used in the future to elucidate the behavioral impact of simultaneously manipulating format and content. Third, the experimental exposure to ads in our study differs from real life, where it is usually repeated over time. Further studies are required to evaluate the brain and behavioral effects of anti-smoking ads in a naturalistic setting. Finally, we did 
not control the emotional tone of ad arguments. Therefore extrapolating our findings to emotionally positive or negative ads would require further experimental validation.

Together, our findings have three immediate theoretical and practical public health implications. First, the strength of ad arguments matters more than its audiovisual presentation: Merely increasing ads' sensory impact may not improve outcomes. Since sensory effects are usually more costly to produce than well thought-through arguments, our observation may be of immediate utility to producers contemplating how to allocate their budgets. Second, since prefrontal BOLD fMRI response to ads may predict their effectiveness, it may have applications in the prerelease evaluation of mass-media video advertising. Finally, by demonstrating the neurophysiological basis of the key concepts in health communication theory, our study sets the stage for science-based evaluation and design of persuasive public health advertising.

\section{References}

Aron AR (2007) The neural basis of inhibition in cognitive control. Neuroscientist 13:214-228. CrossRef Medline

Bandettini PA, Wong EC, Hinks RS, Tikofsky RS, Hyde JS (1992) Time course EPI of human brain function during task activation. Magn Reson Med 25:390-397. CrossRef Medline

Beckmann CF, Smith SM (2004) Probabilistic independent component analysis for functional magnetic resonance imaging. IEEE Trans Med Imaging 23:137-152. CrossRef Medline

Buckner RL, Carroll DC (2007) Self-projection and the brain. Trends Cogn Sci 11:49-57. CrossRef Medline

Burgess PW, Scott SK, Frith CD (2003) The role of the rostral frontal cortex (area 10) in prospective memory: a lateral versus medial dissociation. Neuropsychologia 41:906-918. CrossRef Medline

Cavanna AE, Trimble MR (2006) The precuneus: a review of its functional anatomy and behavioural correlates. Brain 129:564-583. CrossRef Medline

Chua HF, Liberzon I, Welsh RC, Strecher VJ (2009) Neural correlates of message tailoring and self-relatedness in smoking cessation programming. Biol Psychiatry 65:165-168. CrossRef Medline

Chua HF, Ho SS, Jasinska AJ, Polk TA, Welsh RC, Liberzon I, Strecher VJ (2011) Self-related neural response to tailored smoking-cessation messages predicts quitting. Nat Neurosci 14:426-427. CrossRef Medline

Cummings KM (1999) Community-wide interventions for tobacco control. Nicotine Tob Res 1 [Suppl 1]:S113-116. Medline

Dale AM (1999) Optimal experimental design for event-related fMRI. Hum Brain Mapp 8:109-114. CrossRef Medline

Dastjerdi M, Foster BL, Nasrullah S, Rauschecker AM, Dougherty RF, Townsend JD, Chang C, Greicius MD, Menon V, Kennedy DP, Parvizi J (2011) Differential electrophysiological response during rest, selfreferential, and non-self-referential tasks in human posteromedial cortex. Proc Natl Acad Sci U S A 108:3023-3028. CrossRef Medline

Demb JB, Desmond JE, Wagner AD, Vaidya CJ, Glover GH, Gabrieli JD (1995) Semantic encoding and retrieval in the left inferior prefrontal cortex: a functional MRI study of task difficulty and process specificity. J Neurosci 15:5870-5878. Medline

den Ouden HE, Frith U, Frith C, Blakemore SJ (2005) Thinking about intentions. Neuroimage 28:787-796. CrossRef Medline

Donohew L, Lorch EP, Palmgreen P (1998) Applications of a theoretic model of information exposure to health interventions. Hum Commun Res 24:454-468. Medline

Durkin S, Brennan E, Wakefield M (2012) Mass media campaigns to promote smoking cessation among adults: an integrative review. Tob Control 21:127-138. CrossRef Medline

Emery S, Kim Y, Choi YK, Szczypka G, Wakefield M, Chaloupka FJ (2012) The effects of smoking-related television advertising on smoking and intentions to quit among adults in the United States: 1999-2007. Am J Public Health 102:751-757. CrossRef Medline

Falk EB, Berkman ET, Mann T, Harrison B, Lieberman MD (2010) Predicting persuasion-induced behavior change from the brain. J Neurosci 30 : 8421-8424. CrossRef Medline

Falk EB, Berkman ET, Whalen D, Lieberman MD (2011) Neural activity during health messaging predicts reductions in smoking above and beyond self-report. Health Psychol 30:177-185. CrossRef Medline

First M (2002) Diagnostic and statistical manual of mental disorders, Ed 4 (First M, ed), text revision. Washington DC: American Psychiatric Association.

Fishbein M (2000) The role of theory in HIV prevention. AIDS Care 12: 273-278. CrossRef Medline

Fishbein M, Cappella J (2006) The role of theory in developing effective health communications. J Commun 56: S1-S17. CrossRef

Fishbein M, Hennessy M, Kamb M, Bolan GA, Hoxworth T, Iatesta M, Rhodes F, Zenilman JM (2001a) Using intervention theory to model factors influencing behavior change. Project RESPECT. Eval Health Prof 24:363384. CrossRef Medline

Fishbein M, Triandis HC, Kanfer FH, Becker MH, Middlestadt SE, Eichler, A. (2001b) Factors influencing behavior and behavior change. Mahwah, NJ: Lawrence Erlbaum.

Fishbein M, Hall-Jamieson K, Zimmer E, von Haeften I, Nabi R (2002a) Avoiding the boomerang: testing the relative effectiveness of antidrug public service announcements before a national campaign. Am J Public Health 92:238-245. CrossRef Medline

Fishbein M, Cappella J, Hornik R, Sayeed S, Yzer M, Ahern R (2002b) The role of theory in developing effective anti-drug public service announcement. Mawah, NJ: Lawrence Erlbaum.

Fox MD, Snyder AZ, Vincent JL, Corbetta M, Van Essen DC, Raichle ME (2005) The human brain is intrinsically organized into dynamic, anticorrelated functional networks. Proc Natl Acad Sci U S A 102:9673-9678. CrossRef Medline

Gabrieli JD, Poldrack RA, Desmond JE (1998) The role of left prefrontal cortex in language and memory. Proc Natl Acad Sci U S A 95:906-913. CrossRef Medline

Geiger S, Reeves B (1993) The effects of scene changes and semantic relatedness on attention to television. Commun Res 20:155-175. CrossRef

Gibbons FX, Gerrard M, Blanton H, Russell DW (1998) ) Reasoned action and social reaction willingness and intention as independent predictors of health risk. J Pers Soc Psychol 74:1164-1180. CrossRef Medline

Gilbert SJ, Bird G, Frith CD, Burgess PW (2012) Does "task difficulty" explain "task-induced deactivation?". Front Psychol 3:125. CrossRef Medline

Gusnard DA, Raichle ME (2001) Searching for a baseline: functional imaging and the resting human brain. Nat Rev Neurosci 2:685-694. CrossRef Medline

Gusnard DA, Akbudak E, Shulman GL, Raichle ME (2001) Medial prefrontal cortex and self-referential mental activity: relation to a default mode of brain function. Proc Natl Acad Sci U S A 98:4259-4264. CrossRef Medline

Hasson U, Malach R, Heeger DJ (2010) Reliability of cortical activity during natural stimulation. Trends Cogn Sci 14:40-48. CrossRef Medline

Heatherton TF, Kozlowski LT, Frecker RC, Fagerström KO (1991) The Fagerstrom Test for Nicotine Dependence: a revision of the Fagerstrom Tolerance Questionnaire. Br J Addict 86:1119-1127. CrossRef Medline

Hersey JC, Niederdeppe J, Ng SW, Mowery P, Farrelly M, Messeri P (2005) How state counter-industry campaigns help prime perceptions of tobacco industry practices to promote reductions in youth smoking. Tob Control 14:377-383. CrossRef Medline

Indovina I, Macaluso E (2007) Dissociation of stimulus relevance and saliency factors during shifts of visuospatial attention. Cereb Cortex 17: 1701-1711. Medline

Jardri R, Pins D, Bubrovszky M, Despretz P, Pruvo JP, Steinling M, Thomas P (2007) Self awareness and speech processing: an fMRI study. Neuroimage 35:1645-1653. CrossRef Medline

Jenkinson M, Smith S (2001) A global optimisation method for robust affine registration of brain images. Med Image Anal 5:143-156. CrossRef Medline

Jenkinson M, Bannister P, Brady M, Smith S (2002) Improved optimization for the robust and accurate linear registration and motion correction of brain images. Neuroimage 17:825-841. CrossRef Medline

Johnson JA, Zatorre RJ (2006) Neural substrates for dividing and focusing attention between simultaneous auditory and visual events. Neuroimage 31:1673-1681. CrossRef Medline

Kang Y, Cappella JN, Fishbein M (2006) The attentional mechanism of message sensation value: interaction between message sensation value 
and argument quality on message effectiveness. Commun Monogr 73: 351-378. CrossRef

Kwong KK, Belliveau JW, Chesler DA, Goldberg IE, Weisskoff RM, Poncelet BP, Kennedy DN, Hoppel BE, Cohen MS, Turner R (1992) Dynamic magnetic resonance imaging of human brain activity during primary sensory stimulation. Proc Natl Acad Sci U S A 89:5675-5679. CrossRef Medline

Laird AR, Eickhoff SB, Li K, Robin DA, Glahn DC, Fox PT (2009) Investigating the functional heterogeneity of the default mode network using coordinate-based meta-analytic modeling. J Neurosci 29:14496-14505. CrossRef Medline

Lancaster JL, Woldorff MG, Parsons LM, Liotti M, Freitas CS, Rainey L, Kochunov PV, Nickerson D, Mikiten SA, Fox PT (2000) Automated Talairach atlas labels for functional brain mapping. Hum Brain Mapp 10:120-131. CrossRef Medline

Langleben DD, Loughead JW, Ruparel K, Hakun JG, Bush-Winokur S, Holloway MB, Strasser AA, Cappella JN, Lerman C (2009) Reduced prefrontal and temporal processing and recall of high "sensation value" ads. Neuroimage 46:219-225. CrossRef Medline

Lee S, Cappella JN, Lerman C, Strasser AA (2011) Smoking cues, argument strength, and perceived effectiveness of antismoking PSAs. Nicotine Tob Res 13:282-290. CrossRef Medline

Meltzer JA, McArdle JJ, Schafer RJ, Braun AR (2010) Neural aspects of sentence comprehension: syntactic complexity, reversibility, and reanalysis. Cereb Cortex 20:1853-1864. CrossRef Medline

Morgan SE (2003) Associations between message features and subjective evaluations of the sensation value of antidrug public service announcements. J Commun 53:512-526. CrossRef

Morris JD, Klahr NJ, Shen F, Villegas J, Wright P, He G, Liu Y (2009) Mapping a multidimensional emotion in response to television commercials. Hum Brain Mapp 30:789-796. CrossRef Medline

Norman P, Conner M, Bell R (1999) The theory of planned behavior and smoking cessation. Health Psychol 18:89-94. CrossRef Medline

Northoff G, Bermpohl F (2004) Cortical midline structures and the self. Trends Cogn Sci 8:102-107. CrossRef Medline

Oldfield RC (1971) The assessment and analysis of handedness: the Edinburgh inventory. Neuropsychologia 9:97-113. CrossRef Medline

Park HS, Levine T, Kingsley Westerman C, Orfgen T, Foregge S (2007) The effects of argument quality and involvement type on attitude formation and attitude change: a test of dual-process and social judgment predictions. Hum Commun Res 33:81-102.

Petty RE, Cacioppo JT (1986) Communication and persuasion: central and peripheral routes to attitude change New York: Springer.

Phan KL, Wager T, Taylor SF, Liberzon I (2002) Functional neuroanatomy of emotion: a meta-analysis of emotion activation studies in PET and fMRI. Neuroimage 16:331-348. CrossRef Medline

Poldrack RA (2007) Region of interest analysis for fMRI. Soc Cogn Affect Neurosci 2:67-70. Medline

Pomerleau CS, Carton SM, Lutzke ML, Flessland KA, Pomerleau OF (1994) Reliability of the Fagerstrom Tolerance Questionnaire and the Fagerstrom Test for Nicotine Dependence. Addict Behav 19:33-39. CrossRef Medline

Raichle ME, MacLeod AM, Snyder AZ, Powers WJ, Gusnard DA, Shulman GL (2001) A default mode of brain function. Proc Natl Acad Sci U S A 98:676-682. CrossRef Medline

Rao H, Wang J, Tang K, Pan W, Detre JA (2007) Imaging brain activity during natural vision using CASL perfusion fMRI. Hum Brain Mapp 28:593-601. CrossRef Medline

Rossiter JR, Silberstein RB, Harris PG, Nield GA (2001) Brain-imaging de- tection of visual scene encoding in long-term memory for TV commercials. J Advert Res 41:13-21.

Sly DF, Hopkins RS, Trapido E, Ray S (2001) Influence of a counteradvertising media campaign on initiation of smoking: the Florida "truth" campaign. Am J Public Health 91:233-238. CrossRef Medline

Smith SM (2002) Fast robust automated brain extraction. Hum Brain Mapp 17:143-155. CrossRef Medline

Snodgrass JG, Corwin J (1988) Pragmatics of measuring recognition memory: applications to dementia and amnesia. J Exp Psychol Gen 117:34-50. CrossRef Medline

Sobell L, Sobell M (1992) Timeline follow-back: a technique for assessing self-reported alcohol consumption. In: Measuring alcohol consumption (Litten R, Allen J, eds), pp 41-72. Clifton, NJ: Humana.

Soon CS, Brass M, Heinze HJ, Haynes JD (2008) Unconscious determinants of free decisions in the human brain. Nat Neurosci 11:543-545. CrossRef Medline

SRNT Subcommittee on Biochemical Verification (2002) Biochemical verification of tobacco use and cessation. Nicotine Tob Res 4:149-159. CrossRef Medline

Stephenson M, Benoit W, Tschida D (2001) Testing the mediating role of cognitive responses in the elaboration likelihood model. Commun Studies 52:324-337. CrossRef

Strasser AA, Cappella JN, Jepson C, Fishbein M, Tang KZ, Han E, Lerman C (2009) Experimental evaluation of antitobacco PSAs: effects of message content and format on physiological and behavioral outcomes. Nicotine Tob Res 11:293-302. CrossRef Medline

Toro R, Fox PT, Paus T (2008) Functional coactivation map of the human brain. Cereb Cortex 18:2553-2559. CrossRef Medline

Updegraff JA, Sherman DK, Faith S, Luyster FS, Mann TL (2007) The effects of message quality and congruency on perceptions of tailored health communications. J Exp Soc Psychol 43:249-257. CrossRef Medline

Vincent JL, Kahn I, Snyder AZ, Raichle ME, Buckner RL (2008) Evidence for a frontoparietal control system revealed by intrinsic functional connectivity. J Neurophysiol 100:3328-3342. CrossRef Medline

Wakefield M, Szczypka G, Terry-McElrath Y, Emery S, Flay B, Chaloupka F, Saffer H (2005) Mixed messages on tobacco: comparative exposure to public health, tobacco company- and pharmaceutical companysponsored tobacco-related television campaigns in the United States, 1999-2003. Addiction 100:1875-1883. CrossRef Medline

Whitfield-Gabrieli S, Moran JM, Nieto-Castañón A, Triantafyllou C, Saxe R, Gabrieli JD (2011) Associations and dissociations between default and self-reference networks in the human brain. Neuroimage 55:225-232. CrossRef Medline

Whittingstall K, Bartels A, Singh V, Kwon S, Logothetis NK (2010) Integration of EEG source imaging and fMRI during continuous viewing of natural movies. Magn Reson Imaging 28:1135-1142. CrossRef Medline

WHO (2012) WHO global report: mortality attributable to tobacco. New York: World Health Organization.

Woolrich MW, Ripley BD, Brady M, Smith SM (2001) Temporal autocorrelation in univariate linear modeling of FMRI data. Neuroimage 14: 1370-1386. CrossRef Medline

Zhang S, Li CS (2012) Functional connectivity mapping of the human precuneus by resting state fMRI. Neuroimage 59:3548-3562. CrossRef Medline

Zhao X, Strasser A, Cappella J, Lerman C, Fishbein M (2011) A measure of perceived argument strength: reliability and validity in health communication contexts. Commun Methods Measures 5:48-75. CrossRef

Zhu Z, Hagoort P, Zhang JX, Feng G, Chen HC, Bastiaansen M, Wang S (2012) The anterior left inferior frontal gyrus contributes to semantic unification. Neuroimage 60:2230-2237. CrossRef Medline 